\title{
Surface Contaminant Control Technologies to Improve Laser Damage Resistance of Optics
}

\author{
Xiaofeng Cheng, Xinxiang Miao, Hongbin Wang, Lang Qin, Yayun Ye, Qun He, \\ Zhiqiang Ma, Longbiao Zhao, and Shaobo He
}

Research Center of Laser Fusion, China Academy of Engineering Physics, Mianyang 621900, China

Correspondence should be addressed to Xiaofeng Cheng; cxf67@163.com

Received 1 March 2014; Revised 5 June 2014; Accepted 12 June 2014; Published 29 June 2014

Academic Editor: Haiyan Xiao

Copyright (c) 2014 Xiaofeng Cheng et al. This is an open access article distributed under the Creative Commons Attribution License, which permits unrestricted use, distribution, and reproduction in any medium, provided the original work is properly cited.

\begin{abstract}
The large high-power solid lasers, such as the National Ignition Facility (NIF) of America and the Shenguang-III (SG-III) laser facility of China, can output over 2.1 MJ laser pulse for the inertial confinement fusion (ICF) experiments. Because of the enhancement of operating flux and the expansion of laser driver scale, the problem of contamination seriously influences their construction period and operation life. During irradiation by intense laser beams, the contaminants on the metallic surface of beam tubes can be transmitted to the optical surfaces and lead to damage of optical components. For the high-power solid-state laser facilities, contamination control focuses on the slab amplifiers, spatial filters, and final-optical assemblies. In this paper, an effective solution to control contaminations including the whole process of the laser driver is put forward to provide the safe operation of laser facilities, and the detailed technical methods of contamination control such as washing, cleanliness metrology, and cleanliness protecting are also introduced to reduce the probability of laser-induced damage of optics. The experimental results show that the cleanliness level of SG-III laser facility is much better to ensure that the laser facility can safely operate at high energy flux.
\end{abstract}

\section{Introduction}

The laser-induced damage in high-power laser system is an important problem, and contamination control methods of high-power solid-state laser drivers also play important roles. At the beginning of the development of high-power solid-state laser drivers, the contamination problems are not prominent because of the low laser energy flux. With the expansion of the driver's scale and the increase of laser energy flux, new requirements of the damage resistance capacity of the facility components are put forward. The previous approaches for laser driver operation could not meet the new requirements, and the environment contamination in laser facilities may degrade the optics damage threshold and so limit further development of the laser drivers. Today, Shenguang-III (SG-III) laser facility, which is composed of 48 square laser beams $(400 \mathrm{~mm} \times 400 \mathrm{~mm})$, is under construction, and it can output hundreds of thousands of joules of the UV laser pulse per nanosecond [1]. Owing to the enlightenment of the construction of the National Ignition Facility (NIF) in the United States, the contamination control of the SG-III laser facility has been unprecedentedly considered during construction because of the laser-induced damage with contamination located on the optic surface. As the largest high-power solid-state laser driver in the world, NIF is a pioneer of the human exploration of new energy, but its construction is not easy. The "management storm" that occurred in 1999 thoroughly revealed the scientific and technical problems in the development of laser driver. One of the problems is that the nonstrict pollution-control led to the extension of construction period and increase of fund [2]. Contamination control of the high-power solid-state laser driver covers the entire process of design, processing, construction, and operation. The technical support of contamination control includes precision cleaning, cleanliness testing, and product protection. The contamination control is necessary for many important components in the highpower solid-state laser, such as slab amplifiers, spatial filters, 
and final-optics assembly, because the slab amplifiers provide tens of thousands of times of laser pulse gain, and their inside is irradiated by strong internal flash with intensity of about $10 \mathrm{~J} / \mathrm{cm}^{2}$. Those expensive optical components inside the amplifier are susceptible to being contaminated or damaged. Therefore it is the primary task to control the pollution of the laser driver. Because the level of cleanliness for the amplifier's safe operation is unknown $[3,4]$ and the largescale damage-free laser glass cannot be manufactured in the engineering [5], it is essential to obtain the level of cleanliness as high as possible. To improve the cleanliness inside the slab amplifier, the optimized design of its structure should be first considered in favor of the contamination control [6-9]. By optimizing the clean process [10] and standardizing the contamination control [11], the initial cleanliness can be obtained to meet the requirement. In addition, by using the strong flash light irradiation, the residual organic contaminants on the surface or under the subsurface can be drastically removed [12].

In this paper, the methods of contamination control to reduce the damage probability of optics during construction of the SG-III facility are described in detail. The cleanliness of SG-III laser facility has been significantly improved by the contamination control in the entire process. For example, the cleanliness of the slab amplifiers of SG-III laser facility has been unprecedentedly improved. Through the flash light cleaning experiments, the cleanliness level of the SG-III laser facility is better than that of other laser facilities, and the probability of the laser-induced damage owing to the contamination descends. The results show that the SG-III laser facility developed independently by China is one of the cleanest large-scale high-power solid-state lasers in the world.

\section{Laser-Induced Damage due to Contamination in SG-III Laser Facility}

It has been observed that various levels of damage occur to laser glass during normal laser operations [9, 13-15]. The damage phenomenon has nearly always been associated with the introduction of extrinsic (external) particulate contamination such as the inadvertent exposure of gaskets to laser resulting in the generation of massive amounts of burned particles which form an aerosol and eventually settle everywhere inside the laser cavity.

Usually, when the aerosol level is maintained in the range above 5000 particles $/ \mathrm{ft}^{3}$ in the cavity, the particles tend to land on the laser glass material. When a dust particle lands on laser glass surface, laser-induced damage is initiated by absorbing particles and results in small pits. The particles on or near the glass surface absorb the laser energy, and the surface is rapidly heated by laser shots to the plasma temperature of about $10000 \mathrm{~K}$ [16]. The particles often melt and redeposit in the surroundings. The surface morphology is that of a burnt surface with a large number of small craters, as shown in Figure 1. During the irradiation of subsequent shots, the laser interacts with the expanded contaminant dot and evaporates it and plasma ignites until a majority of the contaminant is ablated completely. At the same time, a damage site appears

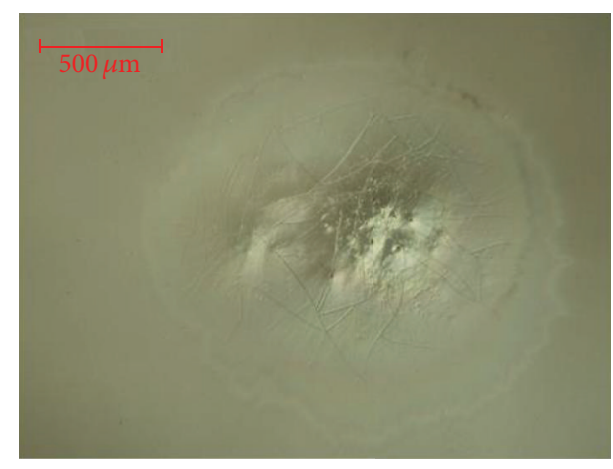

Figure 1: Microscopic image of laser-induced damage owing to contamination on optic surface.

at the area of optical surface. The damage site is not stable and grows or changes upon further irradiation until the catastrophic damage occurs. The contamination in highpower laser facility plays an important role in laser-induced damage of optics, and the higher cleanliness level is required during high-power laser facility operation. The pollutants such as inorganic particulate and liquid organic residues are required to be strictly controlled in the high-power solid-state laser driver. The surface cleanliness testing, clean washing, cleanliness protection, and flash light irradiation cleaning are the key points of the contamination control of the high-power solid-state laser facility.

\section{Methods of Contamination Control for Components in ICF Drivers}

To obtain the higher cleanliness level, there are many methods of contamination control in laser facility. The surface cleanliness means the relative degree of the aggregation of the residual contamination on the solid surface. For the high-power solid-state lasers, cleanliness level of the surface should contain two relatively independent components, that is, particulate pollution and nonvolatile residue.

The definition of the surface cleanliness follows the rules drafted by IEST-STD-CC1246E [17]. For the beam path of the SG-III laser facility, we developed a quantitative standard of the cleanliness control for the SG-III laser facility. For the high-flux aperture optics, the cleanliness level of its surface is required to reach the class $50-\mathrm{A} / 10$. And for the mechanical components, the cleanliness level of the surface is required to the class $100-\mathrm{A} / 10$.

For the clean methods, Stowers indicated that the highpressure spray cleaning method can remove more than $99.9 \%$ of the pollutant with diameter larger than $5 \mu \mathrm{m}$ in several seconds [18]. Comparing with the ultrasonic cleaning and chemical solution cleaning, the cleaning efficiency is improved in the range of $20 \%$ to $60 \%$. Compared with other cleaning methods, the high-pressure spray cleaning has advantages of high cleaning efficiency, convenience and flexibility, low-cost, and so forth. It is also the best choice for the cleaning of large mechanical facilities. In 2001, a cleaning team led by Doug Larson specifically studied the cleaning 

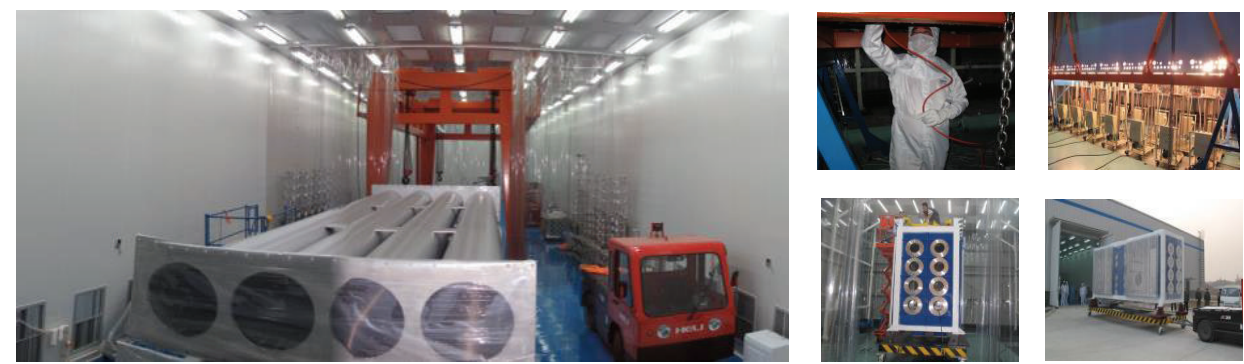

FIGURE 2: Small-batch production line for large mechanical structure cleaning.
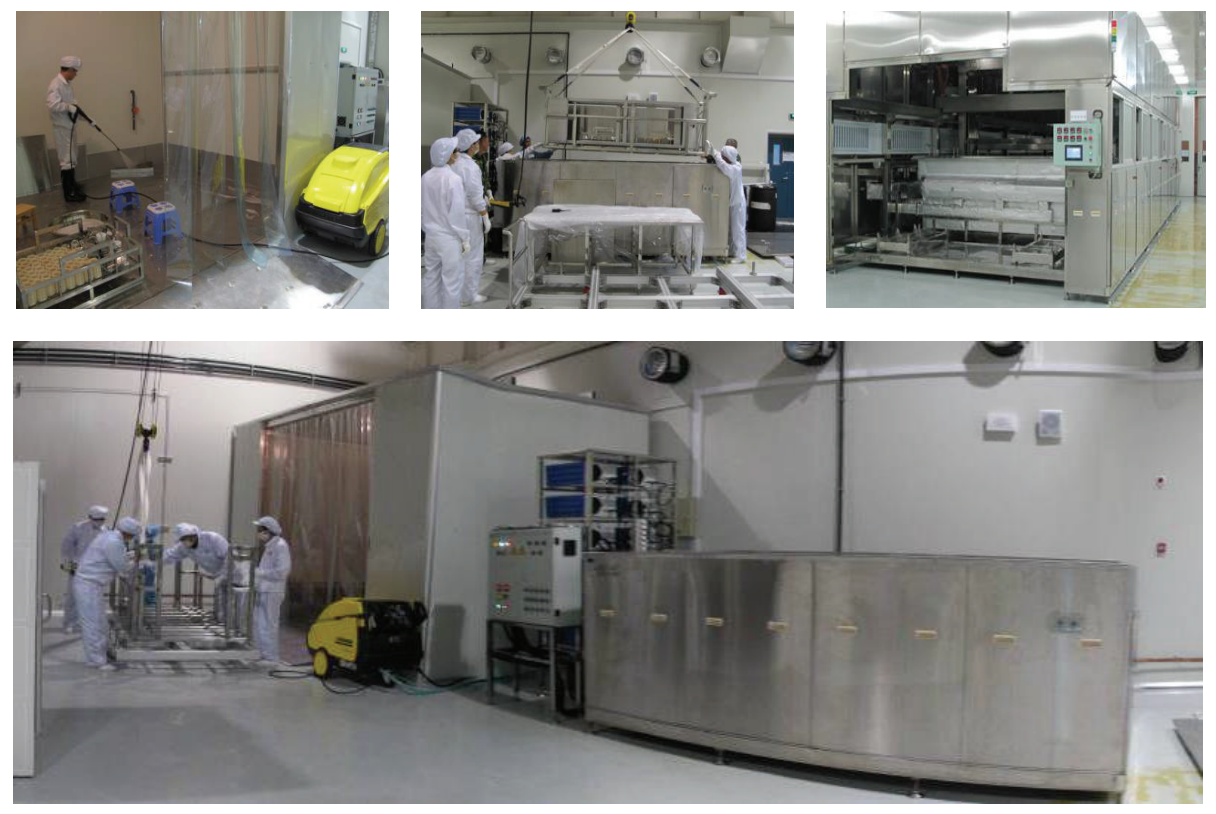

FIGURE 3: Small-batch production line for LRU modules.

process of the NIF amplifier frame assembly unit (FAU) [10]. They confirmed the feasibility of the high-pressure spray cleaning for the sophisticated cleaning technique and identified that the cleanliness level needed for the NIF can be reached by requiring strict compliance with the cleaning standards and procedures. They also verified that the use of surfactants Brulin 1990GD has no corrosive effect on the components. The organic surfactants can be removed easily, and there will be no residual if used properly.

According to the construction requirement of SG-III laser facility, two small-batch clean production lines have been built, one of which is a clean washing line for large mechanical structure parts, as shown in Figure 2. The production line is built outside of the facility but adjacent to the building. The cleaning level inside the clean production lines is ISO class 6 , with an area of about $320 \mathrm{~m}^{2}$. The cleaning plant is divided into four regions, that is, rough cleaning area, fine cleaning area, baking area, and packaging area. All of the precise cleaning tasks of large mechanical structure parts are completed in the cleaning plant. High-pressure spray cleaning method is chiefly adopted.

The other cleaning line, as shown in Figure 3, is for the precision cleaning of the linear-replaceable-unit (LRU) modules. The cleaning techniques adopted are high-pressure spray cleaning, single-slot low-frequency ultrasonic cleaning, six-slot ultrasonic cleaning system, and so forth. The highpressure spray cleaning and single-slot low-frequency ultrasonic cleaning are rough cleaning. The workshop environment is ISO class 8 . After the rough cleaning, the cleanliness level of the work pieces has reached the requirements measured by the water-film rupture method. Then, the work pieces are sent into the six-slot ultrasonic cleaning system to continue fine cleaning, and the environment of the system is ISO class 6.

In order to reach the best cleaning effect in the SG-III laser facility, the cleaning control is carried out by using the hierarchical control method in the entire process. The cleanliness levels of various functional zones are shown in 
TABLE 1: Controlling airborne particulate cleanliness in every cleaning room or zone in SG-III laser driver.

\begin{tabular}{lc}
\hline Controlled cleaning room or zone & $\begin{array}{c}\text { Airborne particulate } \\
\text { cleanliness level }\end{array}$ \\
\hline Mounting zone & ISO 5 \\
Optics assembly workshop & ISO 5 \\
Precision cleaning building & ISO 6 \\
Gross cleaning workshop & ISO 8 \\
Laser beam tube & ISO 4 \\
Optics/LRU protecting case & ISO 5 \\
Target area, laser hall & ISO 8 \\
\hline
\end{tabular}

Table 1, and the classification of the cleaning levels of the air employs the international standard ISO 14644-1 [19]. The air cleanliness level inside the optical transmission channel of the laser facility reaches ISO class 4 , so the optical components can be kept clean for a long time. To protect the components or modules from secondary pollution in a short period, the cleanliness of the workshop of precision assembly, installation site, and the cleaning keeping box of the optics components and linear-replaceable-unit (LRU) is required to reach the ISO class 5 . The cleanliness level of precision cleaning plant is required to reach ISO class 6 and the cleanliness level of the rough cleaning plant, laser hall, and target region needs to reach ISO class 8. Such clean plant design takes into account both cleaning requirements during facility construction and operation. The costs of the construction and operation are also effectively controlled.

\section{Flash Light Irradiation Cleaning}

Slab amplifier is the core part of the high-power solid-state laser facility, and the validation of the clean control was performed first on the disk amplifier system. First, LRU modules, such as slab amplifier, slab boxes, and flash light boxes, need an acid washing process before rough cleaning. The purpose of the acid washing process is to effectively remove the surface residual grease, especially the organic matter residual after machining process. Next, LRU modules need rough cleaning and fine cleaning. After that, LRU modules are installed inside the amplifier container. After that, by using the high-pressure spray cleaning, ultrasonic cleaning process is to complete the precision cleaning of the large container and LRU. Finally, LRU modules and container are baked by a long infrared light, which is helpful not only to remove the residual moisture on the surface and subsurface, but also to remove volatile organic residues on regional surface and subsurface.

In order to effectively control the cleanliness, the flash light irradiation cleaning is a specific cleaning process for slab amplifiers. With the flash light irradiation, the aerosols are generated with the exposure of the residual organic contaminants on mechanical surface and subsurface. With a higher flash light energy, all the residual organic contaminants would sustain damage. Through those methods, the residual organic contaminants can be reduced. Two kinds of improvements of the design have been made about the amplifier to lower probability of collisions between the aerosol particles and the slab surfaces. One is that the clean nitrogen and clean air purge system are designed inside the amplifier slab boxes and flash light boxes, and the other is that a fast filtering unit (FFU) purge system is designed on the top of the amplifier $[6,8]$. The purpose of the designed clean nitrogen and clean air purge system inside amplifier slab boxes and flash light boxes is to replace the large amount of aerosol generated inside the laser facility. The clean nitrogen and clean air can reduce the residence time of aerosol inside the laser facility and decrease the contamination of optical components. At the same time, the purge system also acts as an air knife, and it can purge the depositions of particulate pollutants on the optical surface to some extent. The IESTSTD-1246 class 100 in the optical components can be reached for about $5 \mathrm{~min}$. The FFU purge system on the top of amplifier is to get a clean environment during the process of installation or replacement of light boxes and also to protect the optical module installed from contamination. In addition, a bottom installation car is designed specifically for the clean installation of the amplifier, the LRU modules, flash light boxes, slab boxes, and so forth. The bottom installation car has a clean container, providing the clean environment for the transportation and field installation of the module.

\section{Results and Discussion}

The measure of the surface cleanliness includes two parts: particulate pollutants and nonvolatile residues. The method for the quantitative measurement often used for the residual particulate contamination on the surface is microscopic counting method [20]. The measurement procedure includes sample collection, microscopic analysis, and data processing. According to the surface density of the particulate contamination with different diameters, the level of cleanliness can be calculated. The usual method for the quantitative measurement of nonvolatile residues on the surface is the gravimetric method [21]. By using the following steps, such as sampling, drying, weighing, and other steps, the cleanliness level can be obtained based on the surface density of the mass of the nonvolatile residues.

The 304 stainless steel is extensively used in LRUs in SGIII project. Through the methods of the high-pressure spray cleaning experiments, the surface cleanliness level is shown in Figures 4 and 5. We performed the high-pressure spray cleaning experiments. By optimizing the main parameters of cleaning process, the important technological parameters such as distance of washing, cleaning speed, and cleaning temperature are obtained and the cleaning effect meets the precision cleaning requirements.

Figure 4 shows the relationship between the surface contact angle of the 304 stainless steel work pieces and the number of cleaning steps. The contact angle measurement is usually used to achieve an approximate result of surface NVR as a fast testing method [22]. There were three groups of identical stainless steel samples used in this experiment. And they were, respectively, labeled Sample 1 to Sample 3. 


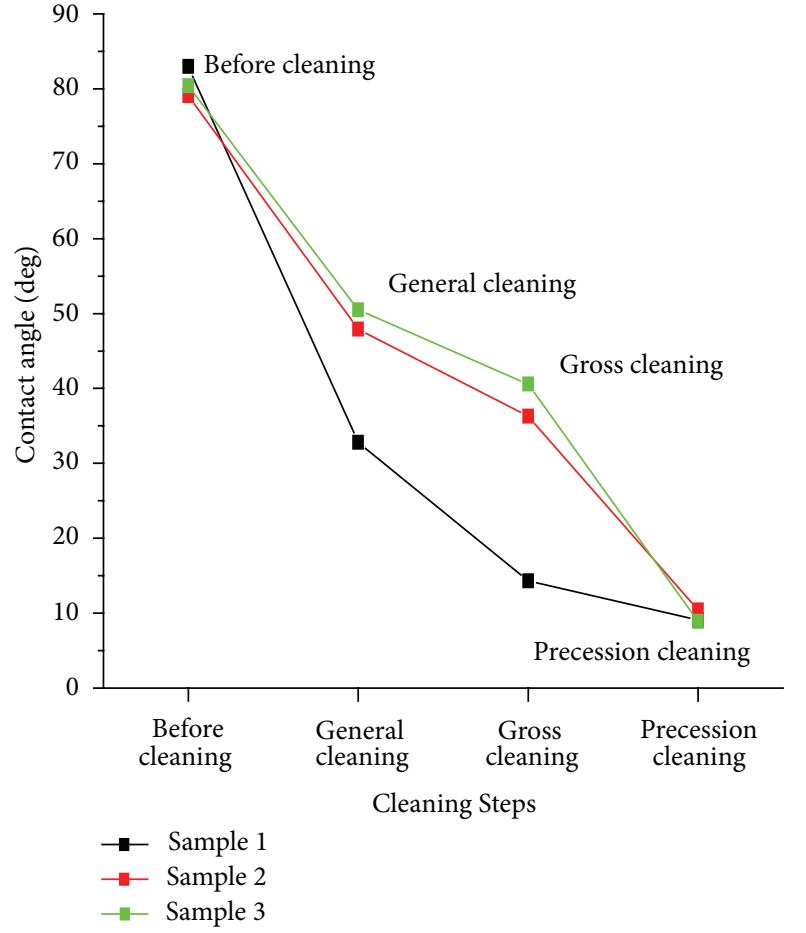

FiguRE 4: Curves of contact angle versus processing steps.

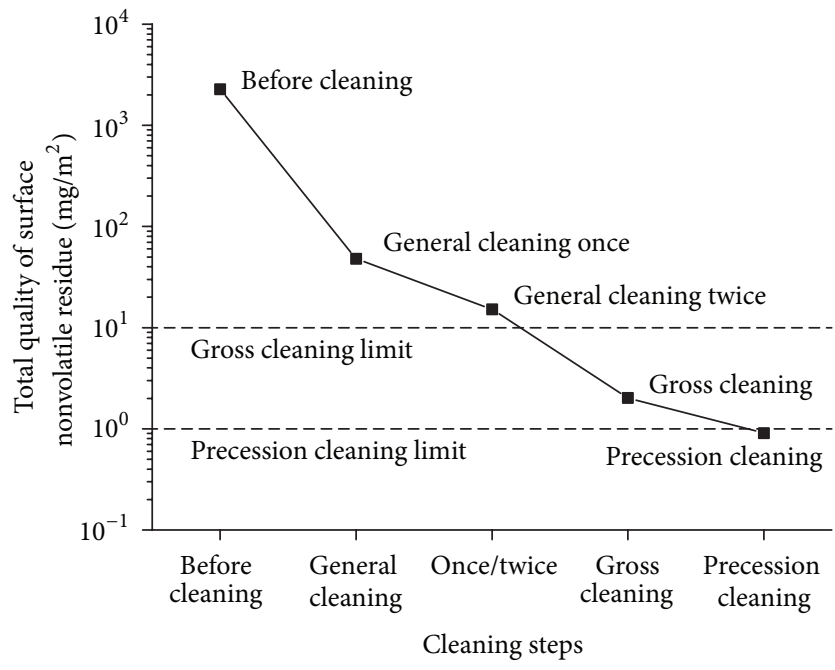

FIGURE 5: Curves of NVR versus processing steps.

By comparison with the cleaning effects of the three samples, the contact angle of the surface changes at different cleaning stages. All the surface contact angles are close to the intrinsic contact angle of material after the precision cleaning. There is a direct relation between the surface contact angle of work piece and surface cleanliness. By testing the contact angle, the surface cleanliness can be obtained indirectly.

Figure 5 illustrates the trend curve of nonvolatile residual (NVR) in 304 stainless-steel work piece surfaces at different cleaning stages by using the gravimetric method. Before cleaning, the NVR on the sample surface is about $260 \mathrm{mg} / \mathrm{m}^{2}$.

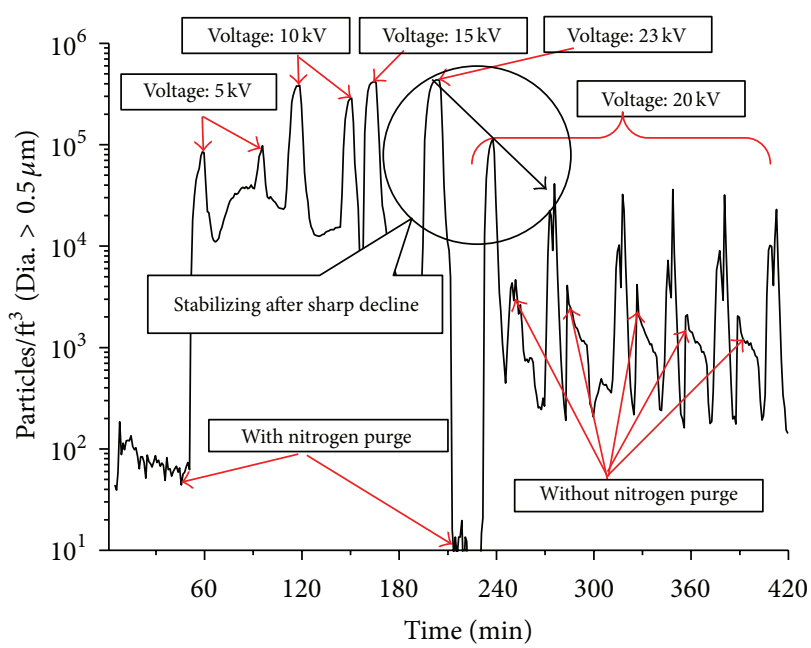

FIGURE 6: Plot of the SG-III slab amplifier aerosol concentrations during the first flashlamp shots.

After rough cleaning, the NVR decreases to $10 \mathrm{mg} / \mathrm{m}^{2}$, meeting class A cleanliness level. After precise cleaning, the NVR dropped below $1 \mathrm{mg} / \mathrm{m}^{2}$, reaching A/10 cleanliness level. The residual particulate contamination on the surface of the 304 stainless steel was measured by the microscopic count method after precision cleaning, and the results show that the cleanliness level is better than grade 100-A/10.

There are about 60 shots of flash light irradiation cleaning experiments for slab amplifiers with clean frame assembly unit but without Nd-glass slabs to be performed [23, 24]. The data of aerosol recorded inside the slab amplifier of Bundle A5 of SG-III laser facility are shown in Figures 6 and 7. The air cleanliness level is evaluated by the volume concentration of the aerosol with particle size larger than $0.5 \mu \mathrm{m}$. The changes of cleanliness of the first 12 shots inside the amplifier slab box are shown in Figure 5, and the changes of cleanliness of the last few shots are shown in Figure 6. In Figures 5 and 6 , the abscissas indicate the time with unit of minutes, and the ordinates indicate aerosol particle concentrations in the amplifier cavity. And the curves show the aerosol particle concentrations in the amplifier cavity vibrating during and after amplifier flashlamp "shots."

In Figure 6, the experiments of the 1st to 5th shots are debugging by low-voltage flash energy and 1st to 4th shots are by using a single module. Generally, the higher the input voltage of the flash light, the more thorough the decomposition of the residual organic pollutants and the higher the aerosol concentrations. For the 1st and 2nd shots, the input voltage of the flash is $5 \mathrm{kV}$, and after flash, the aerosol levels generated are about 70,000 to 80,000 particles/ $/ \mathrm{ft}^{3}$. For the 3rd and 4th shots, the input voltage of the flash is $10 \mathrm{kV}$, and the aerosol level for the $3 \mathrm{rd}$ shot is 310,000 particles $/ \mathrm{ft}^{3}$, and for the 4th shot the aerosol level quickly decreased to 230,000 particles $/ \mathrm{ft}^{3}$. For the 5 th shot, all the flash lights of the entire amplifier module are tested together, and the input voltage is $15 \mathrm{kV}$, and the generated aerosol level is 340,000 particles $/ \mathrm{ft}^{3}$. The input voltage for 6 th shot is 


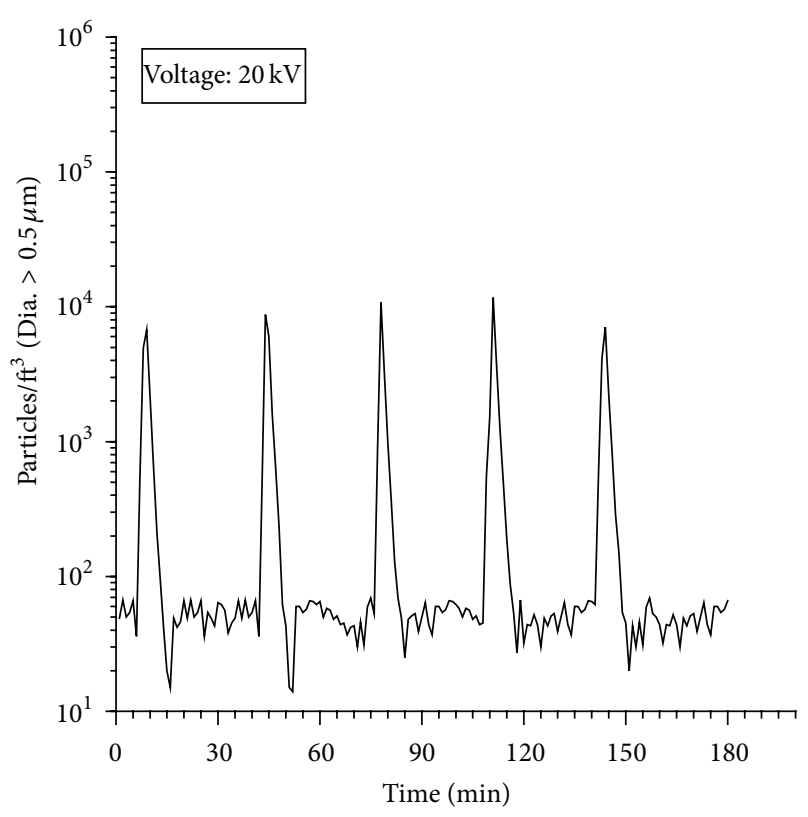

FIGURE 7: Plot of the SG-III slab amplifier aerosol concentrations during the last flashlamp shots.

$23 \mathrm{kV}$, and after the 6th shot, the flash light cleaning was performed with all the flash input voltage of $20 \mathrm{kV}$. It can be observed that, for the 6th, 7th, and 8th shots, the aerosol levels decrease rapidly. For the 6th shot, the aerosol level is 360,000 particles $/ \mathrm{ft}^{3}$, while for the 7 th shot, the aerosol level quickly reduced to 90,000 particles/ $/ \mathrm{ft}^{3}$ and only about 30,000 particles/ $/ \mathrm{ft}^{3}$ for the 8 th shot. The rapid decrease of the aerosol levels suggests that the decomposition of organic matters and the release of aerosol take place at the beginning of the flash light cleaning experiments. After the 8th shot, the aerosol level became steady and just decreased slowly till the end of the flash light cleaning, and these changes implied that the decomposition of organic pollutants occurred less and less with the number of the flash light irradiation shots increasing.

The volume concentration of the aerosol of the last 5 shots of the entire flash light cleaning experiments is shown in Figure 7. The aerosol levels inside the amplifier are maintained in the range of 5,000 to 10,000 particles/ $/ \mathrm{ft}^{3}$, and the levels are close to the cleanliness of the NIF facility and far higher than that of NOVA, Beamlet, and other similar facilities [12], including Shenguang-III prototype of China.

Through the contamination control methods above, the quiescent aerosol in the laser cavity is generally below class 5. The cumulative size distribution of damage (or surface obscurations) on slab and optics surfaces has been measured and it is found that it is related to the size distribution of the aerosols that appear after a flashlamp firing. In general, all SG-III facility slabs have less damage after removing the contamination. And it is generally believed that the amount of damage is also a function of the cleaning level and numbers of aerosol contaminants. These results show that the contamination control methods are effective to improve the laser damage resistance of optics.

\section{Conclusions}

Quantitative pollution-control project is effectively implemented during the construction of the SG-III laser facility to reduce the laser-induced damage probability owing to the contamination, and its clean condition is largely improved compared with other high-power solid-state laser facilities. The pollution-control project also led to the technological improvement of precession washing, cleanliness test, and clean control. Experiments of the flash light cleaning of slab amplifier confirmed the great effect of the clean control. The aerosol concentration obtained by flash light cleaning experiments in the SG-III facility is slightly higher than that obtained in the NIF facility, and the difference may relate to materials and structures of the amplifier and input voltage of light flash during light cleaning. For NIF light cleaning, the input voltage of the flash is $23 \mathrm{kV}$, while for the SG-III, the input voltage is $20 \mathrm{kV}$. With the higher input voltage, the irradiation temperature of the flash will be higher, and the residual organic contaminants on the surface will decompose more thoroughly, and the aerosol concentrations become much lower after the cleanliness of the amplifier. With the increase of the number of light cleaning shots, the total amount of aerosol pollutants decreased, while the types of pollutants increased. The reason is that macromolecules of organic pollutants decompose into small molecules with bright light irradiation, and the details of the changes need be further studied. The contamination control of high-power solid-state laser facility should also include the running process, so that the clean control of the entire process of laser facility can be carried out, and the technical support should be provided for the laser equipment of more security, stability, and efficiency.

\section{Conflict of Interests}

The authors declare that there is no conflict of interests regarding the publication of this paper.

\section{Acknowledgments}

The authors acknowledge colleagues for their support in experiments described in this paper. The authors also thank Professor Guo Feng from Southwest University of Science and Technology for his contribution to writing this paper.

\section{References}

[1] X. T. He and W. Y. Zhang, "Inertial fusion research in China," European Physical Journal D, vol. 44, no. 2, pp. 227-231, 2007.

[2] C. Macilwain, "Laser project "faces optics hardle"', Nature, vol. 401, no. 6750, pp. 201-202, 1999.

[3] J. Honig and D. Ravizza, "Nova retrospective and possible implications for NIF," Tech. Rep. NIF-0110227, 1999.

[4] G. Meyer, C. Alviso, J. Honig et al., "NVR transport experiments in the offline flashlamp tester," Tech. Rep. NIF-0084527, 2002. 
[5] J. Honig, "Offline slab damage experiments comparing air and nitrogen purge," Tech. Rep. NIF-0070328, 2001.

[6] H. W. Yu, W. G. Zheng, J. Tang et al., "Investigation of slab cavity cleanliness of high power laser amplifiers," High Power Laser and Particle Beams, vol. 13, no. 3, pp. 272-276, 2001.

[7] J. A. Horvath, "NIF/LMJ prototype amplifier mechanical design," UCRL-JC-124520, 1996.

[8] H. W. Yu, W. G. Zheng, C. C. Wang et al., "Design and performances of prototype laser amplifiers for technical-integrationline facility," Optical Engineering, vol. 42, no. 3, pp. 725-729, 2003.

[9] I. F. Stowers, J. A. Horvath, and J. A. Menapace, "Achieving and maintaining cleanliness in NIF amplifiers," Tech. Rep. UCRLJC-130040, 1998.

[10] T. H. Shen, "The cleaning of aluminum frame assembly units," UCRL-ID-14393, 2001.

[11] S. Sommer, I. Stowers, and D. van Doren, "Clean construction protocol for the national ignition facility beampath and utilities," Journal of the IEST, vol. 46, pp. 85-97, 2003.

[12] J. Honig, "Cleanliness improvements of National Ignition Facility amplifiers as compared to previous large-scale lasers," Optical Engineering, vol. 43, no. 12, pp. 2904-2911, 2004.

[13] K. Bien-Aimé, C. Belin, L. Galláis et al., "Impact of storage induced outgassing organic contamination on laser induced damage of silica optics at $351 \mathrm{~nm}$," Optics Express, vol. 17, no. 21, pp. 18703-18713, 2009.

[14] J. Neauport, P. Cormont, L. Lamaignère, C. Ambard, F. Pilon, and H. Bercegol, "Concerning the impact of polishing induced contamination of fused silica optics on the laser-induced damage density at $351 \mathrm{~nm}$," Optics Communications, vol. 281, no. 14, pp. 3802-3805, 2008.

[15] G. R. Wirtenson, "High fluence effects on optics in the argus and shiva laser chains," Optical Engineering, vol. 18, no. 6, pp. 574-578, 1979.

[16] M. D. Feit, A. M. Rubenchik, D. R. Faux et al., "Modeling of laser damage initiated by surface contamination," in Proceedings of the Laser-Induced Damage in Optical Materials (SPIE '96), pp. 417-424, October 1996.

[17] E. N. Borson, IEST-STD-CC1246D: Product Cleanliness Levels and Contamination Control Program, 2002.

[18] I. F. Stowers, "Advances in cleaning metal and glass surfaces to micron," Journal of Vacuum Science \& Technology, vol. 15, no. 2, pp. $751-754,1978$.

[19] ISO 14644-1, Cleanrooms and associated controlled environments-part 1: classification of air cleanliness.

[20] R. Chow, R. Bickel, J. Ertel et al., "Cleanliness validation of NIF small optics," in Optical System Contamination: Effects, Measurements, and Control VII, vol. 4774 of Proceedings of SPIE, pp. 19-28, September 2002.

[21] ASTM, E1235-2008, Standard Test Method for Gravimetric Determination of Nonvolatile Residue(NVR) in Environmentally Controlled Areas for Spacecraft, 2008.

[22] R. Kohli and K. L. Mittal, Developments in Surface Contamination and Cleaning: Fundamentals and Applied Aspects, William Andrew, New York, NY, USA, 2008.

[23] X. F. Cheng, X. X. Miao, H. B. Wang et al., "Development on cleanliness control of slab amplifiers for Shenguang-III laser driver," High Power Laser and Particle Beams, vol. 24, no. 1, pp. $1-2,2012$.

[24] X. F. Cheng, H. B. Wang, X. X. Miao et al., "Contamination control for high-power solid-state laser driver and improvement of cleanliness in slab amplifiers," High Power Laser and Particle Beams, vol. 25, no. 5, pp. 1147-1151, 2013. 

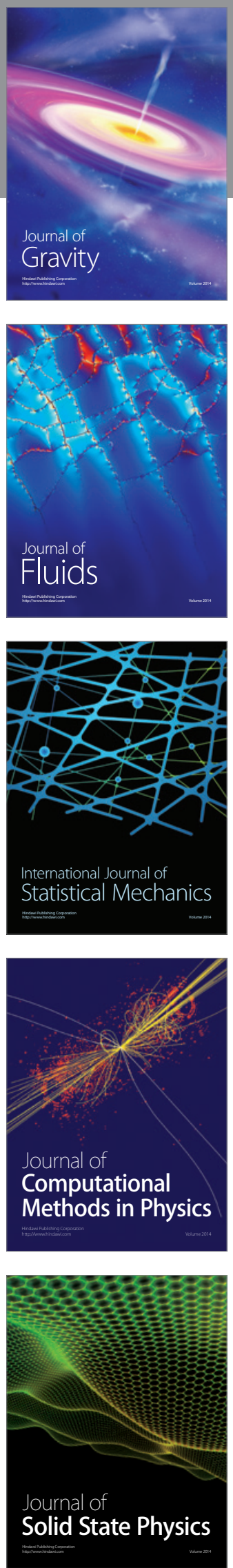

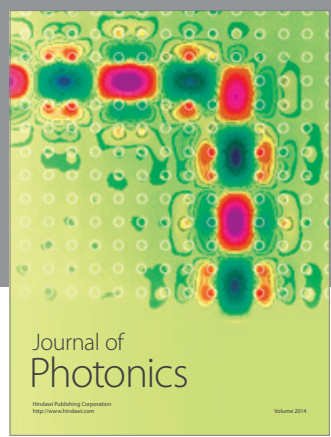

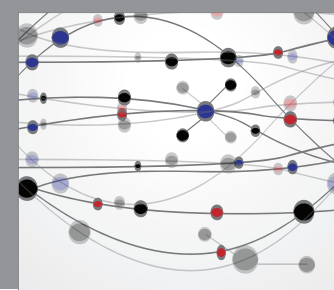

The Scientific World Journal

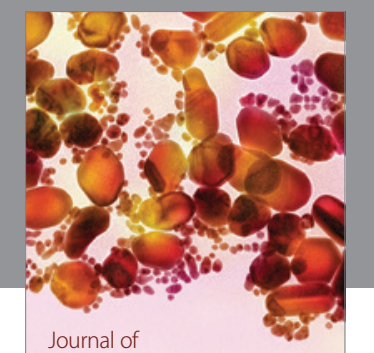

Soft Matter
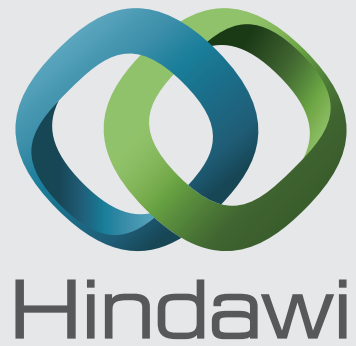

Submit your manuscripts at

http://www.hindawi.com
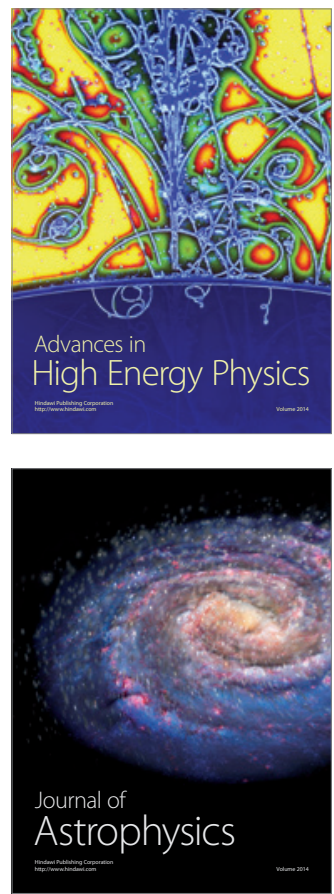
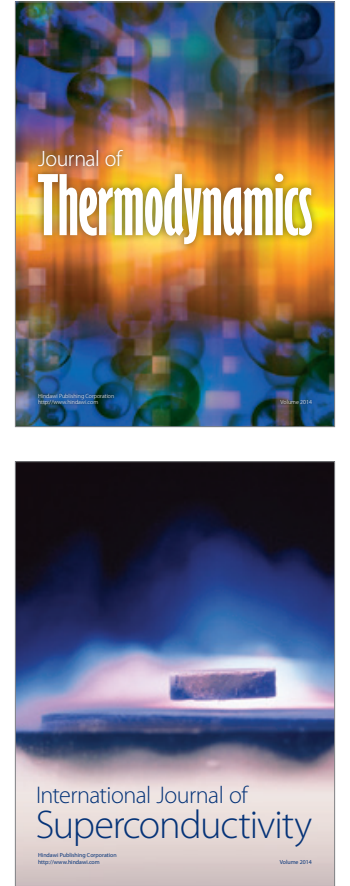
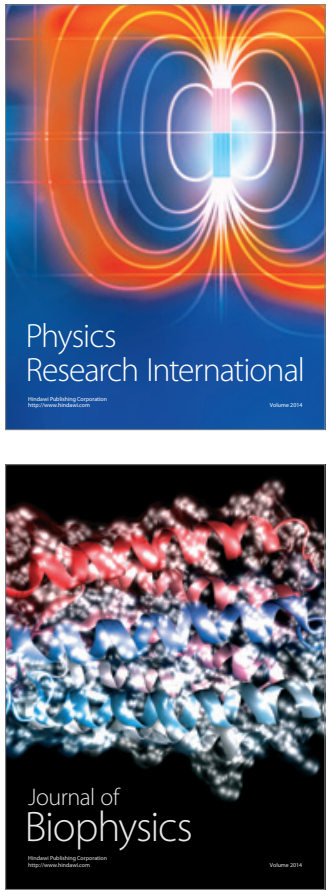
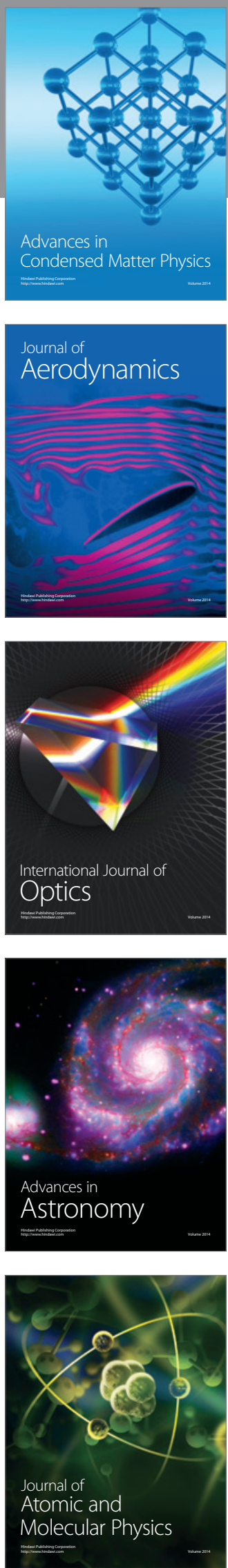